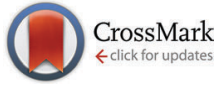

Cite this: J. Mater. Chem. C, 2015 3, 7604

Received 17th March 2015, Accepted 13th June 2015

DOI: $10.1039 / c 5 t c 00753 d$

www.rsc.org/MaterialsC

\title{
Solution processed liquid metal-conducting polymer hybrid thin films as electrochemical $\mathrm{pH}$-threshold indicators $\dagger$
}

\author{
E. Mitraka, ${ }^{a}$ L. Kergoat, ${ }^{a}$ Z. U. Khan, ${ }^{a}$ S. Fabiano, ${ }^{a}$ O. Douhéret, ${ }^{b}$ P. Leclère, ${ }^{b}$ \\ M. Nilsson, ${ }^{c}$ P. Andersson Ersman, ${ }^{c}$ G. Gustafsson, ${ }^{c}$ R. Lazzaroni, ${ }^{b}$ M. Berggren ${ }^{a}$ \\ and X. Crispin ${ }^{\star a}$
}

\begin{abstract}
A global and accurate mapping of the environment could be achieved if sensors and indicators are massproduced at low cost. Printed electronics using polymeric (semi)conductors offer a platform for such sensor/indicator based circuits. Herein, we present the material concept for an electrochemical pH-threshold indicator based on a printable hybrid electrode which comprises a liquid metal alloy (GalnSn) embedded in a conducting polymer matrix (PEDOT). This hybrid electrode displays a large variation in open circuit potential versus $\mathrm{pH}$ in an electrochemical cell, which when connected to the gate of an electrochemical transistor leads to a dramatic change in the drain current in a narrow range of $\mathrm{pH}$.
\end{abstract}

\section{Introduction}

Climate change, disease outbreak, air and water pollution, food quality, ozone holes and acid rain are all related to environmental parameters that we would like to easily map and monitor. One vision is to enable rapidly distribution of low-cost sensors/ indicators by printing them on (news)papers or packages. The sensor/indicator could be activated manually, such that it reads the environmental parameters and sends the information to the internet via a mobile phone. The most important information for environmental mapping is when an environmental parameter exceeds a critical threshold, like a smoke indicator for a fire alarm. Note that some thresholds for environmental parameters might come from limits imposed by political regulations. We define a "threshold indicator" as an indicator that changes state (high and low states) in the output signal when the input signal exceeds a threshold. Threshold indicators can trigger an alarm when pollutant concentration exceeds the threshold for harming the environment. When used for mapping, threshold indicators

\footnotetext{
${ }^{a}$ Department of Science and Technology (ITN), Linköping University, Norrköping, SE-601 74, Sweden. E-mail: xavier.crispin@liu.se

${ }^{b}$ Laboratory for Chemistry of Novel Materials, University of Mons (UMons), Place du Parc 20, 7000 Mons, Belgium

${ }^{c}$ Department of Printed Electronics, Acreo AB, Box 787, Norrköping, SE-60117, Sweden $\dagger$ Electronic supplementary information (ESI) available: Experimental part, droplet size distribution, AFM and C-AFM images of plain PEDOT:Tos, thickness measurement, discussion on the mechanism of PEDOT:Tos reduction after acidic treatment, dependence of conductivity on basic $\mathrm{pH}$, PEDOT work function dependence on $\mathrm{pH}$, and circuit voltage and drain current modulation over basic pH. See DOI: 10.1039/ c5tc00753d
}

allow detecting the areas of concern, i.e. the alarm zones. On the other hand, sensors with a continuous reading (i.e. without a threshold) would lead to a more detailed mapping, and alarm zones are identified afterwards based on threshold values of the sensing parameters. In that aspect, the threshold indicator provides the minimum amount of information for mapping relevant areas.

A global and accurate mapping of the environment could be achieved if indicators are mass-produced at low cost. Printed electronics ${ }^{1}$ using polymeric (semi)conductors offer a platform for such sensor circuits designed for environmental analysis. ${ }^{2}$ One attractive pathway in printed electronics is the design of electrochemical devices, ${ }^{3}$ such as transistors, ${ }^{4}$ memory devices, ${ }^{5}$ pH sensors, ${ }^{6}$ and biosensors, ${ }^{7}$ because they inherently operate at low voltage and are thus compatible with printable battery cells providing typically about $1-2 \mathrm{~V} .{ }^{8}$ There are a few requirements to ensure low-cost manufacturing of the indicators: the materials should be processed from solution and in a few processing steps. A classical strategy to keep the number of fabrication steps limited is to use multifunctional materials, such as conducting polymers, ${ }^{3}$ and to simplify the indicator reading circuit.

The mass manufacturing of devices via printed electronics leads to a broad standard deviation of the device behaviour, ${ }^{9}$ which motivates new tracking methods during device manufacturing. ${ }^{10}$ That is to say, the output signal for different devices shows a broad distribution. ${ }^{11}$ This is one of the major challenges in printed electronics, most specifically printed sensors, since each sensor would need calibration in order to be accurate. On the other hand, threshold indicators are tolerant, i.e. despite a broad distribution of device behaviour, 
the reading maintains a decent accuracy even without calibration. This is because the reading only needs to distinguish between the high-state and the low-state. The reliability of the threshold indicator is further improved when the threshold is introduced as a physico-chemical property at the material level and not at the device level.

In this work, we prove the material concept for a $\mathrm{pH}$-threshold indicator based on a printable hybrid electrode composed of metal particles, with their natural insulating oxide layer, embedded in a conducting polymer matrix. This hybrid electrode displays a large variation in open circuit potential versus $\mathrm{pH}$ in an electrochemical cell. When the hybrid electrode is connected to the gate of an electrochemical transistor, a dramatic change is obtained in the drain current in a narrow range of $\mathrm{pH}$ in harsh acidic environments. The proposed strategy is very different to the large variety of other printed $\mathrm{pH}$-sensors based on the $\mathrm{pH}$ sensitive redox molecule which undergoes a Nernstian potential shift with $\mathrm{pH},{ }^{12,13}$ from which it is not possible to build a threshold indicator without the introduction of a switch circuit.

The material choice and concept beyond the $\mathrm{pH}$-threshold indicator are briefly described. Metals with lower work function than the conducting polymer electrode are appropriate. Indeed, upon solubilizing the oxide layer in an acidic (or basic for amphoteric oxide) environment, the metal and the polymer electrode would then undergo a redox reaction, which shifts the electrode potential. ${ }^{14}$ The electrode potential is expected to vary with $\mathrm{pH}$ and reflects the solubility of the oxide layer versus pH. ${ }^{15}$ The $\mathrm{pH}$ value at which solubility increases depends strongly on the type of metal or alloy as also displayed in Pourbaix diagrams. ${ }^{16}$ While several metal nano/micro-particles are candidates, we investigate the potential of liquid metals. The idea came naturally because of (i) the intrinsic need for solution processable materials in printed electronics, (ii) the demonstration of 3D printing directly liquid metals for electronics, ${ }^{17}$ and (iii) the possibility to control the size of the liquid metal droplets with ultrasonic treatment. The liquid metal is a GaInSn eutectic alloy mainly consisting of gallium (66\%), indium (20.5\%), and tin $(13.5 \%)$, which has a melting point at about $-20{ }^{\circ} \mathrm{C}^{18,19}$ Due to the low toxicity of the component metals, GaInSn finds use as a replacement for many applications that previously employed toxic liquid mercury or a sodium-potassium alloy. In a trace amount of oxygen ( $>1 \mathrm{ppm}$ ), liquid gallium is immediately oxidized forming an oxide shell on the surface of the alloy. ${ }^{19-21}$ This shell consists mainly of gallium oxides $\left(\mathrm{Ga}_{2} \mathrm{O}_{3}\right.$ and $\mathrm{Ga}_{2} \mathrm{O}$ ), whereas metallic gallium is located deeper in the bulk. ${ }^{19,20,22}$ A method to remove this oxide layer is by treating the surface with hydrochloric acid $(\mathrm{HCl}){ }^{19,22}$

To form a composite material with conducting polymers, we were inspired by the strategy used to form gallium-based alloy micro-droplets stabilized in liquids with surfactants, ${ }^{23}$ insulating polymers, ${ }^{23-25}$ and polyelectrolytes ${ }^{26,27}$ for other types of applications ranging from microfluidic reaction engineering, ${ }^{23}$ microelectromechanical system devices (MEMS) ${ }^{25}$ and memristors. ${ }^{26,27}$ One of the novelties in this work is the creation of a hybrid thin film made of GaInSn micro-droplets and the conducting polymer PEDOT:Tos coating.

\section{Results and discussion}

\section{Preparation of the hybrid material}

This composite layer was fabricated by adding a GaInSn drop to a solution of iron(III) tris- $p$-toluene sulphonate $\left(\mathrm{FeTos}_{3}\right)$ and pyridine in butanol. FeTos 3 is the oxidant used for the polymerization of PEDOT-Tos and pyridine acts as an inhibitor of polymerization. ${ }^{28}$ With this inhibitor, the organic solution is stable at room temperature and even under ultrasonication. The metal alloy drop is then shattered into small droplets by ultrasonication. The tosylate anions have some stabilization effect on the micro-droplet suspension similar to longer surfactant molecules. ${ }^{23}$ The monomer 3,4-ethylenedioxythiophene (EDOT) is then added and stirred before spin coating the suspension onto a glass substrate. The polymerization is initiated by annealing the film at $90{ }^{\circ} \mathrm{C}$ (see the Experimental section for more details). It is worth mentioning that despite the high interfacial tension of the liquid alloy, the oxide layer formed during ultrasonication on top of the droplet surface prevents the droplets from coalescing, in agreement with previous reports. ${ }^{23,25,29}$

\section{Morphology of the hybrid material}

The morphology of the composite films was investigated both by Scanning Electron Microscopy (SEM) and (Conductive-)Atomic Force Microscopy (AFM and C-AFM). The SEM images are presented in Fig. 1. A low magnification image (Fig. 1a) reveals a high density of GaInSn micro-droplets, although nano-droplets are also visible at higher magnification (Fig. 1b). The glass substrate that is not covered by metal droplets (bright rough surface) is coated by the conducting polymer (flat darker areas). Fig. 1b displays clearly the presence of a polymer layer covering the nano-droplets. The PEDOT:Tos overlayer is also evidenced by comparing the SEM images taken at high and low acceleration voltage for the same sample area (Fig. 1c and d). With $0.7 \mathrm{kV}$ acceleration voltage (Fig. 1d), the image is more sensitive to the surface of the sample and small liquid metal droplets (visible in Fig. 1c at $5 \mathrm{kV}$ ) are no longer visible due to the PEDOT:Tos coating. A droplet size distribution on a GaInSn-PEDOT:Tos film was estimated by SEM and it follows a power law distribution in the diameter range from $35 \mathrm{~nm}$ to $5500 \mathrm{~nm}$ (see Fig. S1 in the ESI $\dagger$ ).

Typical AFM and C-AFM results are presented in Fig. 2. The AFM image (Fig. 2a) shows a rather rough surface (the vertical scale being around $600 \mathrm{~nm}$ for a $10 \times 10 \mu \mathrm{m}^{2}$ area), which is consistent with the SEM data. The color coding of the image is a reflection of the local deformability of the surface. The major part of the film shows a similar, intermediate deformability (appearing golden in the image), probably corresponding to PEDOT-covered areas. The zones appearing in brown are more rigid; they most probably represent spots where the liquid metal alloy is not coated by the polymer. It is noteworthy that the dark brown areas appear on the same side of the piles, suggesting that the partial coverage is due to the centrifugal character of the spin-coating process. In order to check this assumption, one of these areas was further investigated by C-AFM (Fig. 2b). The image reveals that the surface appearing 

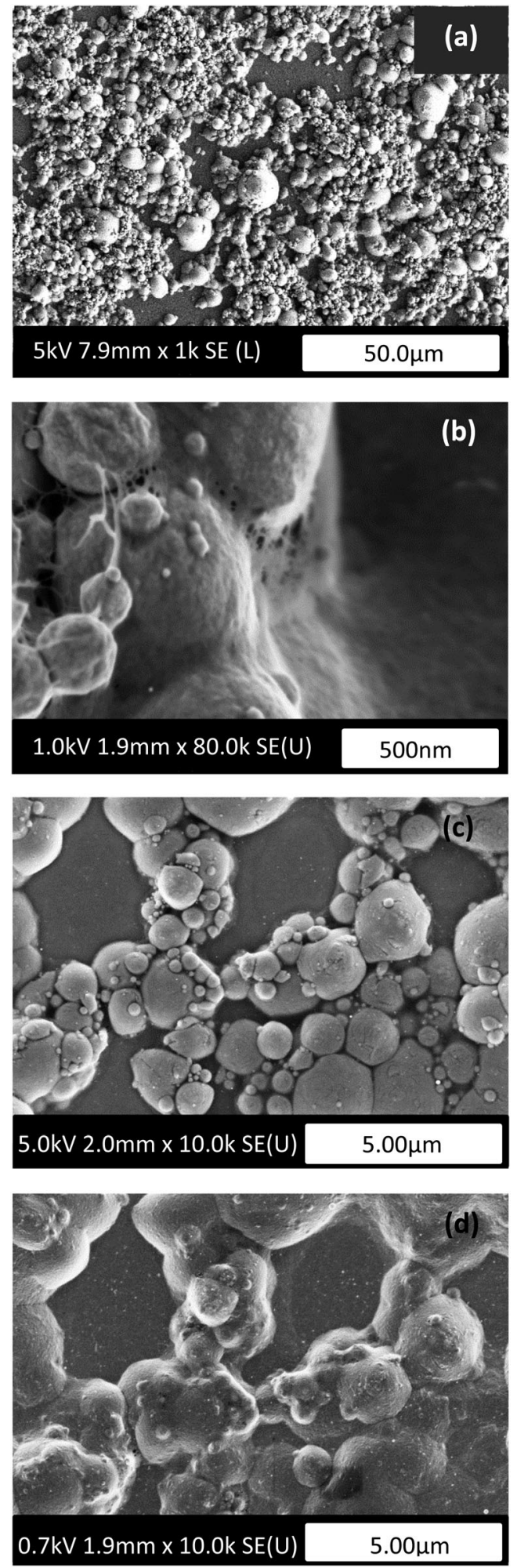

Fig. 1 SEM images of GalnSn-PEDOT:Tos composite films. (a) and (b) show the morphology, respectively, on a $50 \mu \mathrm{m}$ and $500 \mathrm{~nm}$ scale, while (c) and (d) show the same image on a $5 \mu \mathrm{m}$ scale with different acceleration voltages: (c) bulk sensitive at $5 \mathrm{kV}$ and (d) surface sensitive at $0.7 \mathrm{kV}$.

in brown is less conductive than the surrounding area. Since the oxide skin of GaInSn is semiconducting, ${ }^{26,27,30}$ whereas
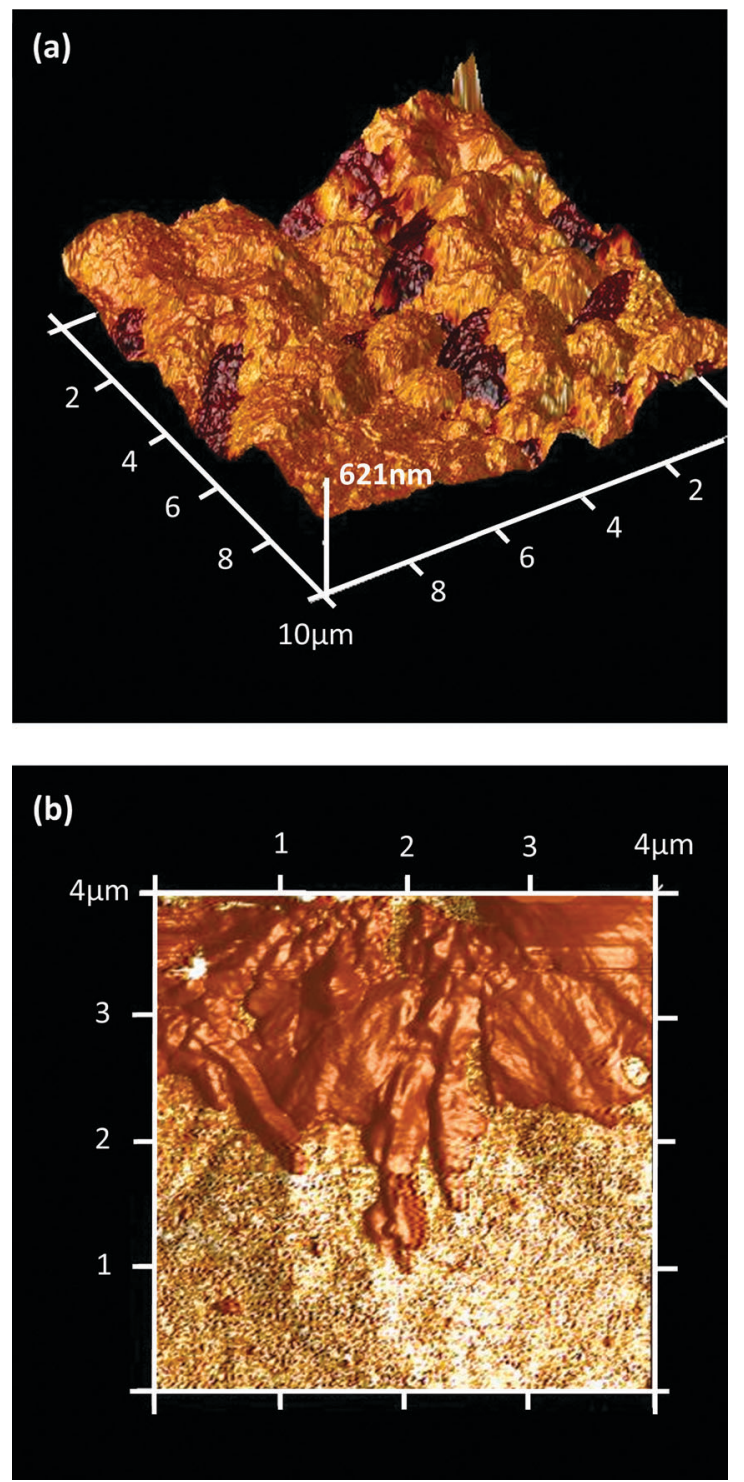

Fig. 2 (a) $10 \times 10 \mu \mathrm{m}^{2}$ AFM image showing simultaneously the topography and the deformability of a GalnSn-PEDOT:Tos film, (b) C-AFM image showing simultaneously the topography and the conductivity of a $4 \times 4 \mu \mathrm{m}^{2}$ area on a GalnSn-PEDOT:Tos film.

PEDOT:Tos is highly conducting, it is reasonable to conclude that in this area the liquid metal particle is not covered by the polymer. We have checked that homogeneous layers of PEDOT:Tos have uniform electrical properties; to illustrate this, Fig. S2 (ESI $\dagger$ ) shows the height and current images of a PEDOT:Tos layer covering an area with an ITO electrode (on the right side) and the bare glass substrate (on the left side). The corresponding current image shows no significant variations despite the strong topographical contrast, confirming the high, uniform conductivity of the polymer.

\section{Electrical and optical properties}

Although the electrical conductivity of gallium-based alloys (without the oxide skin) is that of a metal $\left(\sigma \sim 10^{4} \mathrm{~S} \mathrm{~cm}^{-1}\right.$ at $\left.20{ }^{\circ} \mathrm{C}\right),{ }^{31,32}$ the conductivity of the composite film is only about $500 \mathrm{~S} \mathrm{~cm}^{-1}$, 
which is actually close to typical conductivity values obtained for pristine PEDOT:Tos films. ${ }^{33}$ This suggests that the electrical conductivity of the composite film is actually sustained only by PEDOT:Tos, as GaInSn droplets appear to be electrically isolated by the oxide skin on their surface. As mentioned above, acidic treatment with $\mathrm{HCl}$ is known to remove the oxide layer from the liquid metal droplets. ${ }^{19,22}$ In an attempt to remove the oxide skin from the GaInSn droplets and connect them electrically to the PEDOT:Tos matrix, composite films were dipped in aqueous solutions at various $\mathrm{pH}$ values. The conductivity of both hybrid films and plain polymer films after treatment in solutions at various $\mathrm{pH}$ values is presented in Fig. 3a. Regarding the hybrid films between $\mathrm{pH}=10$ to 4 , the conductivity remains unchanged (average $=435 \mathrm{~S} \mathrm{~cm}^{-1}$ ), but it decreases dramatically when the hybrid films were treated with acidic solutions, from $426 \mathrm{~S} \mathrm{~cm}^{-1}$ at $\mathrm{pH}=4$ to $1.1 \mathrm{~S} \mathrm{~cm}^{-1}$ at $\mathrm{pH}=1$. Importantly, acidic treatment slightly enhances the electrical conductivity of PEDOT:Tos (Fig. 3a), a behaviour which is also confirmed by the literature. ${ }^{34,35}$ Hence the observation of decreased conductivity at low $\mathrm{pH}$ is inherent to the composite and not to PEDOT. The dependence of the conductivity over the whole $\mathrm{pH}$ range is presented in Fig. S4a in the ESI†.

At low $\mathrm{pH}$, the hybrid films turn blue in color, indicating that PEDOT:Tos is reduced and this explains the conductivity drop. This color change of PEDOT upon reduction is well documented in PEDOT-based electrochromic displays. ${ }^{36}$ This reduction is attributed to a spontaneous transfer of electrons from GaInSn to PEDOT:Tos upon removal of the oxide barrier (see ESI $\dagger$ ). The direction of electron transfer is correlated to the Fermi level difference between the metal and the conducting polymer. According to the literature the eutectic galliumindium alloy (EGaIn) has a work function of 4.1-4.2 eV, ${ }^{37}$ while PEDOT:Tos has a higher work function (4.38-4.55 eV in the entire $\mathrm{pH}$ range, see Fig. S5, ESI $\dagger$ ). We hypothesize that the electron transfer is accompanied by the formation of metallic cations $\left(\mathrm{In}^{+}\right.$and $\left.\mathrm{Ga}^{+}\right)$. It is more likely that $\mathrm{In}^{+}$reacts with chloride forming $\mathrm{InCl}_{3}$, which is the dominant component on the surface of the droplets after the acidic treatment. ${ }^{19}$ The electrons released reduce $\mathrm{PEDOT}^{+}$to its neutral, non-conducting state $\left(\right.$ PEDOT $\left.^{0}\right)$ (see ESI $\dagger$ ).

The absorption spectra of hybrid films after treatment in solutions at various $\mathrm{pH}$ values are presented in Fig. $3 \mathrm{~b}$. Note that since the oxide is amphoteric, it also dissolves at high $\mathrm{pH}$, and could potentially lead to a false positive for the $\mathrm{pH}$-indicator (the absorbance data at $\mathrm{pH}>10$ is presented in Fig. S4b in the ESI $\dagger$ ). The absorption band of the pristine composite film extends into the near-infrared (NIR) region, with negligible contribution in the visible region; it strongly resembles that of PEDOT-PSS, due to the presence of (bi)polaron bands. ${ }^{38}$ The bipolaron is a doubly charged defect characterized by an empty level in the band gap of the polymer. PEDOT:Tos is known to form a dense network of bipolarons at an oxidation level as high as $30 \%$. The empty bipolaronic level is distributed in an energy region characterizing an empty bipolaronic band slightly overlapping the valence band. As a consequence of this electronic structure, PEDOT:Tos has a vanishingly small gap and a large NIR
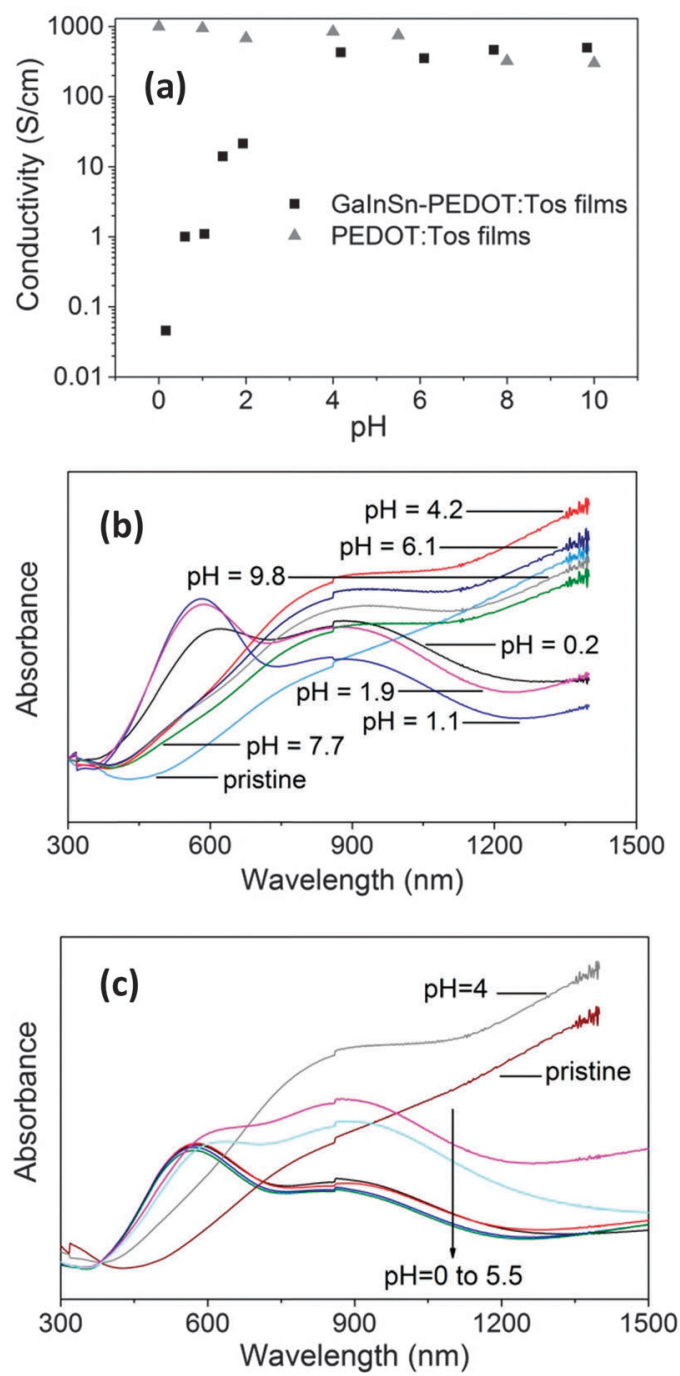

Fig. 3 (a) Conductivity of the GalnSn-PEDOT:Tos films and plain PEDOT:Tos films after treatment in solutions at different $\mathrm{pH}$ values (the conductivities of the GalnSn-PEDOT:Tos films presented here are calculated using the thickness corresponding to Line "a" of Fig. S3, ESI (b) absorption spectra of GalnSn-PEDOT:Tos films after treatment in aqueous $\mathrm{HCl}$ solutions at different $\mathrm{pH}$ values. (c) Absorption spectra of one sample (hybrid film) that is dipped sequentially in various solutions of increasing $\mathrm{pH}$ values from $\mathrm{pH}=0$ to 5.5 . For comparison purposes, the absorption spectra of a pristine hybrid film and that of a film treated just at $\mathrm{pH}=4$ are also included.

absorption background. Upon decreasing the $\mathrm{pH}$, a first new absorption signal appears at $900 \mathrm{~nm}$ and it is attributed to polaronic species. The presence of polarons $(\operatorname{spin}=1 / 2)$ upon PEDOT reduction is indicated by a clear signal in electron spin resonance spectroscopy. ${ }^{39}$ This illustrates that there is first an electron transfer from GaInSn to the bipolaron species to obtain polaron species. ${ }^{40}$ Further decreasing the $\mathrm{pH}$ leads to a lowering of this signal at $900 \mathrm{~nm}$ and the appearance of a new absorption peak at $580 \mathrm{~nm}$ originating from neutral PEDOT $^{0}$ segments. This evolution is attributed to the electron transfer from GaInSn to the polaron species that are in turn transformed into neutral PEDOT chain segments. Hence, the reduction of PEDOT by 
GaInSn occurs in two steps, going from bipolaron to polaron and then to neutral species.

In an attempt to investigate if this reduction of PEDOT on the hybrid film is reversible, we also examined how the absorption spectrum changes when moving from an acidic towards a basic environment. In detail, Fig. 3c displays the absorption spectra of a sample (hybrid film) that is dipped sequentially in various solutions of increasing $\mathrm{pH}$ values from $\mathrm{pH}=0$ to 5.5. For comparison purposes, Fig. $3 \mathrm{c}$ also displays the absorption spectrum of a pristine hybrid film and that of a film treated just at $\mathrm{pH}=4$ (both before any type of acidic treatment). It is easily observed that the spectrum of the pristine hybrid film and that of the film treated at $\mathrm{pH}=4$ show a significant IR background featuring their high electrical conductivity. However, the spectra of the sample which firstly underwent acidic treatment are rather similar and specific to the reduced PEDOT (compare the two spectra at $\mathrm{pH}=4$ - with and without treatment at $\mathrm{pH}=0$ ). Therefore, we conclude that after the hybrid material undergoes acidic treatment, the electrochemical state of PEDOT in the hybrid layer remains reduced irrespective of the $\mathrm{pH}$ values. However, it oxidizes slowly with time when exposed to air but never returns completely back to its initial state. This behavior will give rise to a hysteresis in the electrochemical $\mathrm{pH}$-indicator.

\section{Electrochemical pH-threshold indicator}

The correlation between the change in electrical conductivity (Fig. 3a) and the modification of the optical properties (Fig. 3b) suggests that the electrochemical potential of the composite

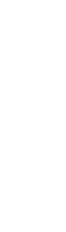

(a)
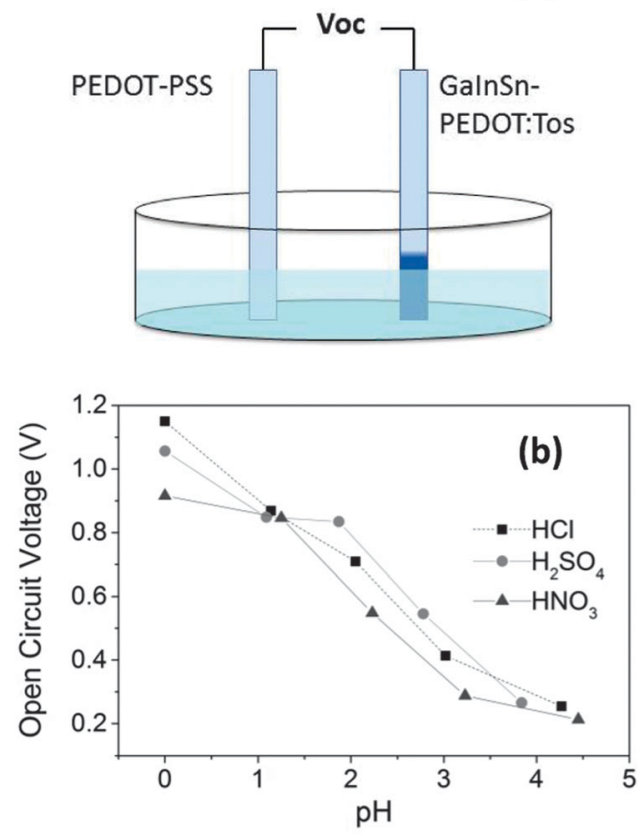

Fig. 4 (a) Schematic description of the arrangement that generates the open circuit voltage $\left(V_{\text {oc }}\right)$ : a PEDOT-PSS strip is dipped simultaneously with a GalnSn-PEDOT:Tos strip in a solution with a specific $\mathrm{pH}$. (b) $V_{\text {oc }}$ measured between two electrodes when dipped in acidic solutions of $\mathrm{HCl}, \mathrm{H}_{2} \mathrm{SO}_{4}$ and $\mathrm{HNO}_{3}$. can also be tuned by $\mathrm{pH}$. The simultaneous immersion of one PEDOT-PSS electrode and one GaInSn-PEDOT:Tos electrode in an acidic aqueous solution (Fig. 4a) generates an open circuit voltage $\left(V_{\mathrm{oc}}\right)$. Fig. $4 \mathrm{~b}$ reports the evolution of the $V_{\mathrm{oc}}$ versus $\mathrm{pH}$ of $\mathrm{HCl}, \mathrm{H}_{2} \mathrm{SO}_{4}$ and $\mathrm{HNO}_{3}$ aqueous solutions (different couple of GaInSn-PEDOT:Tos and PEDOT-PSS electrodes were used for each $\mathrm{pH}$ measurement). We observe that all acids exhibit a high open circuit voltage at low $\mathrm{pH}$, with $\mathrm{HCl}$ exhibiting the highest. In particular, the chemical potential of the PEDOT-PSS electrode is slightly affected in acidic medium. ${ }^{35}$ However, at $\mathrm{pH}<2$, PEDOT:Tos in the presence of GaInSn droplets is reduced and the open circuit voltage reaches even $1.15 \mathrm{~V}$ at $\mathrm{pH}=0$ of an $\mathrm{HCl}$ solution. Thus, monitoring the $V_{\mathrm{oc}}$ for the $\mathrm{HCl}$ solutions (which were found to be the most effective) gives a six-fold variation over the investigated $\mathrm{pH}$ range.

The sensitivity of the $\mathrm{pH}$ indicator can be amplified by connecting the electrochemical cell to an organic electrochemical transistor (OECT). ${ }^{7,41,42}$ The combination of those devices is motivated by their voltage compatibility and use of similar materials (conducting polymer PEDOT and polymer electrolyte). As shown in Fig. 5a (left), OECTs are three-terminal devices. Two electrodes, the source and the drain, are connected by a conducting polymer, poly(3,4-ethylenedioxythiophene) poly(styrenesulfonate) (PEDOT-PSS), forming the channel. The third PEDOT-PSS electrode, the gate, is separated from the channel by a gel electrolyte, here sodium polystyrene sulfonate. The operating principle is based on the modulation of the conductivity of the channel upon gate polarization. ${ }^{42,43}$ In its pristine state, PEDOT-PSS is a p-doped conducting material so a negative bias is applied between the source and the drain to transport holes. When the gate is positively biased, cations from the electrolyte penetrate into the PEDOT-PSS channel, reducing the oxidation level (charge carrier density), hence its conductivity. Typically a low potential $(1 \mathrm{~V})$ at the gate can modulate the current in the channel by several orders of magnitude. We coupled the OECT to the composite/PEDOT-PSS cell (Fig. 5a) so that the $V_{\mathrm{oc}}$ obtained, when dipping the latter in $\mathrm{HCl}$ solutions at various $\mathrm{pH}$ values, is used to shift the gate voltage of the OECT. In an attempt to investigate if the $V_{\text {oc }}$ exhibits the same hysteresis which was observed in the absorption spectra, the same set of composite (GaInSn-PEDOT:Tos) and PEDOT-PSS electrodes were simultaneously immersed from $\mathrm{pH}=7$ to $\mathrm{pH}=0$ and back. The $V_{\text {oc }}$ obtained was applied on the gate of the OECT and it is presented in Fig. 5b. In Fig. 5c, the on/off ratio, which is the ratio between the current in the on-state (no voltage applied on the gate and thus the channel is oxidized) and the current in the off-state (the channel is reduced), is plotted as a function of $\mathrm{pH}$. By immersing the two electrodes at $\mathrm{pH}=7$, we observe that between $\mathrm{pH}=7$ and $\mathrm{pH}=3$, the $V_{\mathrm{oc}}$ is constant and about $0.3 \mathrm{~V}$. In that $\mathrm{pH}$ range, there is no electron transfer reaction between GaInSn and PEDOT:Tos, while the origin of the residual open circuit voltage is attributed to the difference in the work function between PEDOT-PSS and PEDOT:Tos. ${ }^{44}$ The fact that the $V_{\mathrm{oc}}$ remains constant between $\mathrm{pH}=7$ and $\mathrm{pH}=3$ has an impact also on the current modulation (Fig. 5c), which remains stable at a value below 10. Continuing at low $\mathrm{pH}$ values $(\mathrm{pH}<3)$, 

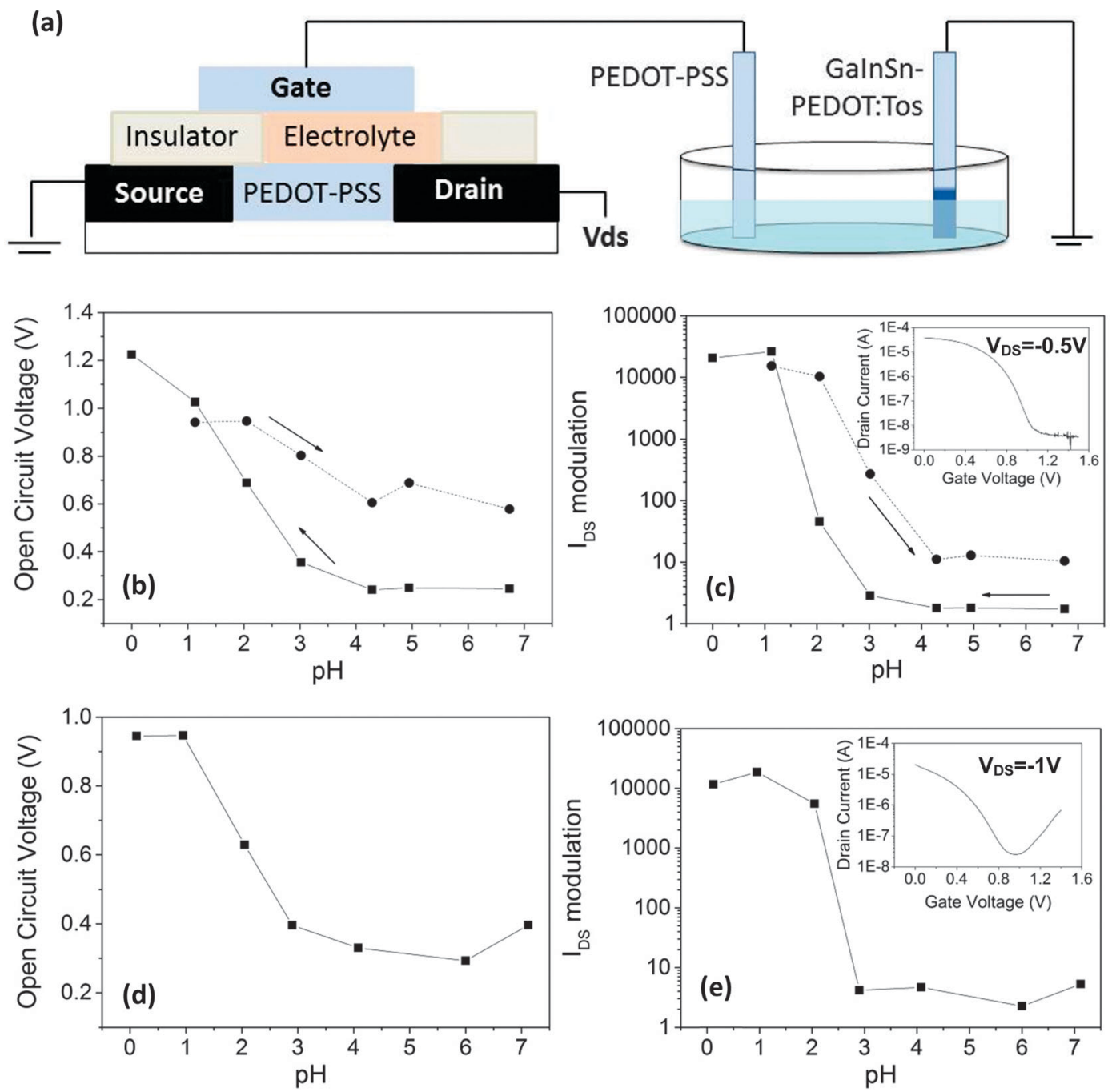

Fig. 5 (a) Schematic description of the pH indicator composed of the electrochemical transistor (left) and the open circuit potential $\left(V_{\text {oc }}\right)$ arrangement (right), the $V_{\text {oc }}$ produced is applied to the gate of the transistor. (b) The $V_{o c}$ measured when the same set of electrodes was immersed sequentially from $\mathrm{pH}=7$ to $\mathrm{pH}=0$ and back. (c) Modulation of the OECT drain current (/DS) when the $V_{\mathrm{oc}}$ of (b) is applied to the gate. The same transistor was used throughout the experiment. The OECT transfer curve is also included. (d) $V_{\mathrm{oc}}$ measured when one new device (device: one transistor and a set of electrodes) was used for each $\mathrm{pH}$ value. (e) $I_{\mathrm{DS}}$ modulation when the $V_{\mathrm{oc}}$ of (d) is applied to the gate of the OECT. The transfer curve presented is a representative of one of the used transistors. Note that the transistor geometry used in (e) is different than in (c).

we observe an abrupt transition of $V_{\mathrm{oc}}$ versus $\mathrm{pH}$ at around $\mathrm{pH}=2$, which is associated with the solubility of gallium oxide as indicated in the Pourbaix diagram of gallium. ${ }^{45}$ At this lower $\mathrm{pH}$, the modulation of the current also increases drastically and reaches 10000 , provoking a $\mathrm{pH}$ threshold of almost four orders of magnitude. Then, moving back to $\mathrm{pH}=7$, we observe that the $V_{\text {oc }}$ (and thus the current modulation) remains high at $\mathrm{pH}=1$ and $\mathrm{pH}=2$ and starts decreasing at $\mathrm{pH}>2$ but without returning to its initial values, exhibiting the same hysteresis which was observed in the absorption spectra. It is worth noting that the threshold which appears in Fig. $5 \mathrm{c}$ within $\mathrm{pH}=1$ and $\mathrm{pH}=2$ should not only be attributed to the sensing ability of the GaInSn-PEDOT:Tos composite. A careful look at the transfer curve of the transistor (Fig. 5b) reveals that the type of OECT used has a very sharp transition for gate voltages within 0.5 and $1 \mathrm{~V}$, while it is smoother for $V_{\mathrm{G}}$ within 0.0 and $0.5 \mathrm{~V}$. For these reasons, the OECT appears to be either "on" (at $\mathrm{pH}>2$, the applied $V_{\mathrm{G}}$ is low and the channel is slightly reduced) or "off" (at $\mathrm{pH}<2$, the applied $V_{\mathrm{G}}$ is higher and thus the channel is further reduced) creating a clear $\mathrm{pH}$ threshold. Note that the $\mathrm{pH}$-threshold can be tuned by the chemical nature of the metal particles in the conducting polymer (different oxides lead to different solubility diagrams $v s$. $\mathrm{pH})^{15}$ as well as to a smaller extent by the geometry of the transistor. ${ }^{46}$

Finally, instead of using the same device, we now take a new set of electrodes for each $\mathrm{pH}$ value (Fig. 5a). It is observed that the $V_{\mathrm{oc}}$ at $\mathrm{pH}>2$ is quite stable around $0.35 \mathrm{~V}$, while at $\mathrm{pH}<2$ the $V_{\text {oc }}$ increases and reaches $0.95 \mathrm{~V}$ at $\mathrm{pH}=0$. The expected evolution of $V_{\text {oc }} v s$. pH (Fig. 5d) indicates that the behavior of the electrode is reproducible. In order to push the threshold to slightly higher $\mathrm{pH}$, the design of the transistor is slightly changed (i.e. the transfer characteristics). A new set of electrodes 
and a new transistor are used for each $\mathrm{pH}$ value in this measurement, and the current modulation in the channel of the OECT is presented in Fig. 5e. Again, the increase in $V_{\mathrm{oc}}$ at $\mathrm{pH}<2$ leads to a current modulation with a threshold larger than three orders of magnitude between $\mathrm{pH}=2$ and $\mathrm{pH}=3$.

\section{Conclusions}

In summary, we present a new electrochemically active printable composite combining the properties of a conducting polymer (PEDOT:Tos) and a liquid metal alloy (GaInSn). Because of the difference in the work function, when the oxide of the liquid metal dissolves in a specific acidic range of $\mathrm{pH}$, it activates a spontaneous electron transfer from GaInSn to PEDOT. The $\mathrm{pH}$ of the medium triggers/activates the change in electrochemical potential and produces voltage up to $1.2 \mathrm{~V}$ in a conducting polymer electrochemical cell. The sensitivity of the $\mathrm{pH}$-threshold is further amplified by four orders of magnitude by coupling the PEDOT-GaInSn electrode to the gate of a fully printed PEDOTbased electrochemical transistor. Further improvements are in progress since the composition of the metal oxide and the work function of the conducting polymer can affect the $\mathrm{pH}$ threshold and the open circuit voltage of the $\mathrm{pH}$-threshold indicator.

\section{Acknowledgements}

The authors acknowledge the European Research Council (ERC-starting-grant 307596), the Swedish Foundation for Strategic Research (Synergy Grant Electronics), the Knut and Alice Wallenberg Foundation (project "Power paper"), The Swedish Energy Agency and the Advanced Functional Materials Center at Linköping University. The authors are grateful to S. Desbief for the AFM control measurements, Mats Eriksson and Julia Netrval working at Spectral Solutions for their assistance in the SEM study and Mats Fahlman for sharing information regarding the work function of PEDOT films. Research at Mons is supported by the European Commission and Région Wallonne (FEDER 'Revêtements Fonctionnels' program, grant no. 475225-579695), BELSPO (project IAP 7/05), the OPTI2MAT Excellence program of Région Wallonne (grant no. 816925), and FNRS-FRFC. P.L. is FRS-FNRS Senior Research Associate.

\section{Notes and references}

1 S. R. Forrest, Nature, 2004, 428, 911-918.

2 O. Knopfmacher, M. L. Hammock, A. L. Appleton, G. Schwartz, J. Mei, T. Lei, J. Pei and Z. Bao, Nat. Commun., 2014, 5, 2954.

3 M. Berggren, D. Nilsson and N. D. Robinson, Nat. Mater., 2007, 6, 3-5.

4 P. Andersson, R. Forchheimer, P. Tehrani and M. Berggren, Adv. Funct. Mater., 2007, 17, 3074-3082.

5 I. Valov, R. Waser, J. R. Jameson and M. N. Kozicki, Nanotechnology, 2011, 22, 254003.

6 B. Lakard, O. Segut, S. Lakard, G. Herlem and T. Gharbi, Sens. Actuators, B, 2007, 122, 101-108.
7 D. A. Bernards and G. G. Malliaras, Adv. Funct. Mater., 2007, 17, 3538-3544.

8 K. Sun, T.-S. Wei, B. Y. Ahn, J. Y. Seo, S. J. Dillon and J. a. Lewis, Adv. Mater., 2013, 25, 4539-4543.

9 A. Pierre, M. Sadeghi, M. M. Payne, A. Facchetti, J. E. Anthony and A. C. Arias, Adv. Mater., 2014, 26, 5722-5727.

10 E. Alarousu, A. AlSaggaf and G. E. Jabbour, Sci. Rep., 2013, 3, 1562 .

11 J. Rivnay, L. H. Jimison, J. E. Northrup, M. F. Toney, R. Noriega, S. Lu, T. J. Marks, A. Facchetti and A. Salleo, Nat. Mater., 2009, 8, 952-958.

12 D. K. Kampouris, R. O. Kadara, N. Jenkinson and C. E. Banks, Anal. Methods, 2009, 1, 25.

13 L. Xiong, C. Batchelor-McAuley and R. G. Compton, Sens. Actuators, B, 2011, 159, 251-255.

14 M. Hilder, B. Winther-Jensen and N. B. Clark, J. Power Sources, 2009, 194, 1135-1141.

15 T. Adschiri, Y. Hakuta, K. Sue and K. Arai, J. Nanopart. Res., 2001, 3, 227-235.

16 D. Cubicciotti, Corrosion, 1988, 44, 875-880.

17 C. Ladd, J.-H. So, J. Muth and M. D. Dickey, Adv. Mater., 2013, 25, 5081.

18 S. K. T. Ravindran, M. Roulet, T. Huesgen, M. Kroener and P. Woias, J. Micromech. Microeng., 2012, 22, 094002.

19 D. Kim, P. Thissen, G. Viner, D.-W. Lee, W. Choi, Y. J. Chabal and J.-B. Lee, ACS Appl. Mater. Interfaces, 2013, 5, 179-185.

20 F. Scharmann, G. Cherkashinin, V. Breternitz, C. Knedlik, G. Hartung, T. Weber and J. a. Schaefer, Surf. Interface Anal., 2004, 36, 981-985.

21 T. L. Liu, P. Sen and C. C. J. Kim, IEEE 23rd International Conference on Micro Electro Mechanical Systems (MEMS), Wanchai, Hong Kong, 2010, p. 560.

22 K. Doudrick, S. Liu, E. M. Mutunga, K. L. Klein, V. Damle, K. K. Varanasi and K. Rykaczewski, Langmuir, 2014, 30, 6867.

23 J. Thelen, M. D. Dickey and T. Ward, Lab Chip, 2012, 12, 3961-3967.

24 M. D. Dickey, R. C. Chiechi, R. J. Larsen, E. A. Weiss, D. A. Weitz and G. M. Whitesides, Adv. Funct. Mater., 2008, 18, 1097-1104.

25 T. Hutter, W.-A. C. Bauer, S. R. Elliott and W. T. S. Huck, Adv. Funct. Mater., 2012, 22, 2624-2631.

26 H.-J. Koo, J.-H. So, M. D. Dickey and O. D. Velev, Adv. Mater., 2011, 23, 3559-3564.

27 J.-H. So, H.-J. Koo, M. D. Dickey and O. D. Velev, Adv. Funct. Mater., 2012, 22, 625-631.

28 B. Winther-Jensen, D. W. Breiby and K. West, Synth. Met., 2005, 152, 1-4.

29 M. R. Khan, C. B. Eaker, E. F. Bowden and M. D. Dickey, Proc. Natl. Acad. Sci. U. S. A., 2014, 111, 14047.

30 H. H. Tippins, Phys. Rev., 1965, 140, A316.

31 X. Liu, L. P. B. Katehi and D. Peroulis, Asia Pacific Microwave Conference, Singapore, 2009, p. 131.

32 C. Karcher, V. Kocourek and D. Schulze, International Scientific Colloquium Modelling for Electromagnetic Processing, Hannover, 2003, p. 105. 
33 O. Bubnova, Z. U. Khan, H. Wang, S. Braun, D. R. Evans, M. Fabretto, P. Hojati-Talemi, D. Dagnelund, J.-B. Arlin, Y. H. Geerts, S. Desbief, D. W. Breiby, J. W. Andreasen, R. Lazzaroni, W. M. Chen, I. Zozoulenko, M. Fahlman, P. J. Murphy, M. Berggren and X. Crispin, Nat. Mater., 2014, 13, 190-194.

34 B. Winther-Jensen and K. West, React. Funct. Polym., 2006, 66, 479-483.

35 M. Yamashita, T. Sasaki, H. Okuzaki and C. Otani, 37th International Conference on Infrared, Millimeter, and Terahertz Waves (IRMMW-THz), Wongong, Australia, 2012, vol. 2.

36 P. Tehrani, L.-O. Hennerdal, A. L. Dyer, J. R. Reynolds and M. Berggren, J. Mater. Chem., 2009, 19, 1799.

37 R. C. Chiechi, E. a Weiss, M. D. Dickey and G. M. Whitesides, Angew. Chem., Int. Ed. Engl., 2008, 47, 142-144.

38 Y. Xuan, M. Sandberg, M. Berggren and X. Crispin, Org. Electron., 2012, 13, 632-637.
39 A. Zykwinska, W. Domagala, A. Czardybon, B. Pilawa and M. Lapkowski, Chem. Phys., 2003, 292, 31-45.

40 K. Jeuris, L. Groenendaal, H. Verheyen, F. Louwet and F. De Schryver, Synth. Met., 2003, 132, 289-295.

41 D. Nilsson, T. Kugler, P. Svensson and M. Berggren, Sens. Actuators, B, 2002, 86, 193-197.

42 P. Andersson Ersman, D. Nilsson, J. Kawahara, G. Gustafsson and M. Berggren, Org. Electron., 2013, 14, 1276.

43 D. Nilsson, N. Robinson, M. Berggren and R. Forchheimer, Adv. Mater., 2005, 17, 353-358.

44 A. Gadisa, K. Tvingstedt, S. Admassie, L. Lindell, X. Crispin, M. R. Andersson, W. R. Salaneck and O. Inganäs, Synth. Met., 2006, 156, 1102-1107.

45 Y. Chung and C.-W. Lee, J. Electrochem. Sci. Technol., 2013, 4, 1-18.

46 J. Rivnay, P. Leleux, M. Sessolo, D. Khodagholy, T. Hervé, M. Fiocchi and G. G. Malliaras, Adv. Mater., 2013, 25, 7010. 